\title{
Field methods of a near-bed suspended sediment experiment in the Yangtze River, China
}

\author{
Caiwen Shu ${ }^{1} \cdot$ Guangming $\operatorname{Tan}^{1} \cdot$ Yiwei $\mathrm{Lv}^{1} \cdot$ Quanxi Xu ${ }^{2}$ \\ Received: 6 September 2019 / Accepted: 6 October 2020 / Published online: 20 October 2020 \\ (C) The Author(s) 2020
}

\begin{abstract}
Using experimental data of near-bed suspended sediment concentrations at five typical hydrometric stations of the Three Gorges Reservoir at the early reserving stage, the differences were investigated between the common method and improved method during flood seasons and non-flood seasons. The impact of taking measurements below 0.2 times the water depth on the results was discussed. The results show that the average discharges and velocities at each station calculated by the common method were slightly larger than those calculated by the improved method. Regarding the suspended sediment concentration at each station, the errors in the reservoir and downstream channels in dynamic equilibrium state were small, and the largest errors occurred where the river bed was strongly scoured in the downstream reach below the large dam. There was no significant relationship between water discharge and flow velocity, and the missed measurement phenomenon also occurred. The sediment discharge error was affected by the suspended sediment concentration, implying that errors usually occurred in channels with serious erosion during flood seasons. The correction coefficients $\left(R^{2}\right)$ of sediment discharge at each station were given during the experiment, which showed that the sediment discharges at the hydrometric stations where a large amount of sediment transport occurred near the river bottom, needed to be modified. Furthermore, the test methods proposed in this study were applied to calculate the sediment discharges of three rivers, and the results indicate that this method can narrow the gap between bathymetric comparisons and sediment load measurements.
\end{abstract}

Keywords Near-bed suspended sediment experiment $\cdot$ Measurement error $\cdot$ Sediment discharge $\cdot$ Correction coefficient

\section{Introduction}

It has long been known that the sediment placed into suspension by flow-induced bottom shear stresses achieves a vertical distribution, which essentially represents a balance between the upward turbulent diffusion and the downward settling of sediment particles (O’Brien 1933; Cacchione et al. 2008;

\section{Responsible Editor: Stefan Grab}

Caiwen Shu

cwshu@whu.edu.cn

$\triangle$ Yiwei Lv

lyw_ns@163.com

1 State Key Laboratory of Water Resources and Hydropower Engineering Science, Wuhan University, Wuhan 430072, Hubei, China

2 Bureau of Hydrology, Changiiang Water Resources Commission, Wuhan 430010, China
Yuan et al. 2017). The process of near-bed sediment transport can be considered as dynamic feedback interactions among the bed, flow, and mobile sediments. According to the "Code for measurement of suspended sediment in open channels" (GB/T 50159-2015) and "Measurement of liquid flow in open channels-Methods for measurement of characteristics of suspended sediment" (ISO 4363:2002), common measurements of suspended sediment (such as the two-point, threepoint and five-point methods) are usually concentrated above 0.2 times the water depth. In natural rivers, this depth is extremely close to the riverbed, so suspended sediment hardly influences the measurement results of suspended load, as proven by Xiang (1988) through experiments on the nearbed suspended sediment of the Yangtze River from 1972 to 1978. However, this view may not fit the situation where a dam is constructed, especially for a large reservoir in highpool level operation. This is because under these conditions, the near-bed suspended sediment may influence the whole suspended load significantly indicating that selecting the measurement point of 0.2 times the water depth is a bit large. After 
reservoir filling, the release of clear water remarkably influences the sediment transport process in the downstream channels (Wang et al. 2018), which therefore affects the accuracy of cross-section sediment discharge measurements. In 1980 and 1981, the hydrology terminus of Sichuan Province, P.R. China, conducted experiments on the near-bed suspended sediment at the Neijiang Station, Dujiang Dam, and the preliminary results also showed that the near-bed suspended sediment significantly influenced the quantity of the suspended load. It can be seen that detecting whether the measurement of nearbed suspended sediment is accurate is of vital importance to improve the accuracies when predicting sediment concentration, sediment discharge, and the yearly suspended sediment discharge. It also reduces the gap between bathymetric comparisons and sediment load measurements.

The current studies on near-bed suspended sediment can be summarized as the following five aspects: (i) Near-bed concentration of suspended sediment. Empirical formulas were established by Smith and McLean (1977), Van Rijn (1984), Celik and Rodi (1988), and Cao (1999) for determining nearbed concentrations of single-sized suspended sediment and by Einstein (1950) and Garcia and Parker (1991) for determining near-bed concentrations of graded suspended sediment. However, each formula can only be applied at the height where the near-bed concentration is defined, making comparisons of these formulas quite difficult. (ii) Near-bed sediment transport. Near-bed sediment transport on continental shelves, estuaries, and lakes has received increasing attention during the last few decades. The objective of these studies is to assess the near-bed sediment transport in estuaries and shelves which are dominated by tides, waves, wave groups, storms, and river flood currents (Drake 1989; Puig and Palanques 2001; Schettini 2002; Palanques et al. 2002; Christopher and Daniel 2002; Liu et al. 2014; Roser et al. 2018; Pang et al. 2019). (iii) Exchanges between near-bottom suspended and sea-bottom sediments. In existing studies, the exact nature of the exchange between suspended and sea-bottom sediment is illuminated, and this aspect is helpful for understanding sediment transport and the fate of suspended sediments in estuarine and coastal areas (Hossain and Eyreb 2002; Jiang and Wang 2005; Ren and Packman 2007). For instance, Liu et al. (2010) examined the spatial variations in the exchange between near-bottom suspended and sea-bottom sediments in the Yangtze Estuary and adjacent regions and explored the fate of suspended sediments in their study areas. (iv) The effect of the near-bed flow regime on the sediment flux. For example, Abelson et al. (1993) proposed that slender bodies in the near-bed flow are better adapted to catch small suspended particles, whereas flat bodies are expected to feed on high fluxes of bed load particles. To quantify how the interaction of such structures with the nearbed flow regime affects the sediment flux, a series of experiments were devised by Friedrichs et al. (2009). (v) New measurement methods. Betteridge et al. $(2002,2003,2008)$ and
Sottolichio et al. (2011) demonstrated the capability of acoustic instrumentation to measure near-bed sediment transport processes in controlled laboratory conditions and in the field. However, previous studies focused on near-bed concentration of suspended sediment, near-bed sediment transport, exchange between near-bottom suspended and sea-bottom sediments, the effect of the near-bed flow regime on the sediment flux, and new measurement methods. And their research objects mainly involve continental shelves, estuaries, and lakes, but few focused on rivers. So in this study, a new sampler has been used to study the near-bed suspended sediment in Yangtze River. And the common method concentrates on depths above 0.2 times the water depth, and the improved method which includes depths below 0.2 times the water depth are compared. In addition, the conditions that must be emphasized in research on near-bed suspended sediment concentrations are given.

\section{Field experiment}

\section{Hydrographic sections}

The Three Gorges Reservoir (TGR) is the largest reservoir worldwide, where the mean depth is close to $70 \mathrm{~m}$, and the maximum depth reaches $175 \mathrm{~m}$ (Wang et al. 2020). Under this condition, 0.2 times the water depth can be up to $14 \mathrm{~m}$, and conventional methods are not applicable when obtaining the near-bed suspended sediment concentration of this area. In addition, the clear water flowing into the downstream channel has a great impact on sediment movement and the evolution of channels. Therefore, it is extremely typical to choose the TGR area and the downstream area of the dam as research sites and to measure the near-bed suspended sediment at these locations. Since 2006, five typical cross-sections have been chosen by the Hydrology Bureau of Changjiang Water Resources Committee, China, for such experiments (CWRC 2017). These sections are Qiangxichang which is in the TGR, $477 \mathrm{~km}$ upstream off the dam; Wanxian which is also in the TGR, $289 \mathrm{~km}$ upstream of the dam; Yichang which is $44 \mathrm{~km}$ downstream of the dam and $6 \mathrm{~km}$ upstream of the Gezhou Dam; Shashi and Jianli which are $208 \mathrm{~km}$ and $346 \mathrm{~km}$ downstream of the Three Gorges Dam, respectively; and Jianli which is $6 \mathrm{~km}$ upstream of the Jianli staff gauge station (Fig. 1). The five typical cross-sections are Qiangxichang, Wanxian, Yichang, Shashi, and Jianli. Among them, the Qiangxichang and Wanxian are all in the TGR, but they are $477 \mathrm{~km}$ and $289 \mathrm{~km}$ upstream off the dam, respectively. The Yichang is $44 \mathrm{~km}$ downstream of the dam and $6 \mathrm{~km}$ upstream of the Gezhou Dam. Moreover, the Shashi and Jianli are $208 \mathrm{~km}$ and $346 \mathrm{~km}$ downstream of the Three Gorges Dam, respectively. And Jianli is $6 \mathrm{~km}$ upstream of the Jianli staff gauge station (Fig. 1) 
Fig. 1 Sketch location of each section

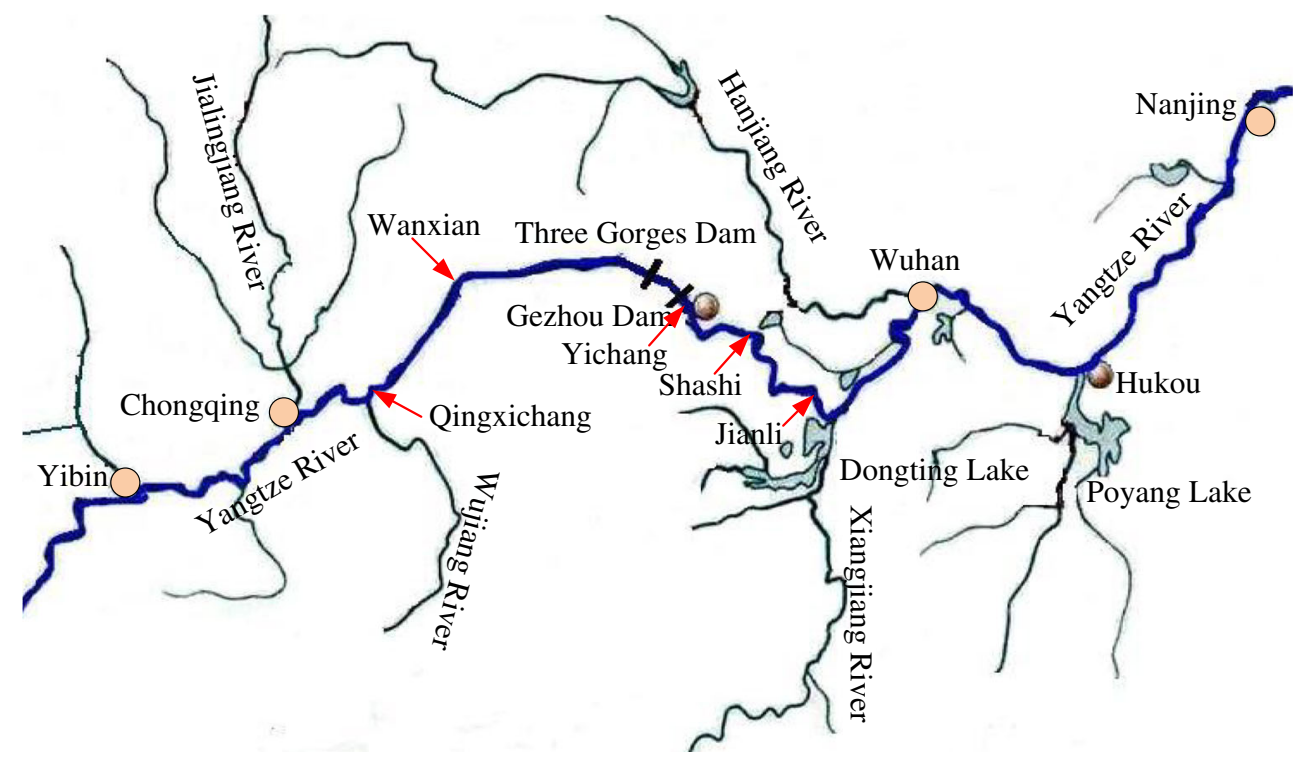

\section{Test data}

From Jun. 2006 to Jul. 2007, experiments were performed at the test sections according to the incoming water and sediment regime. Usually, one test per month was conducted in the dry season, $2-3$ tests were conducted in the flood season, and 3-5 tests were conducted during large floods. During the observation season, the Yangtze River was in the dry year; therefore, there were thirteen, fourteen, and eight tests performed at Qingxichang, Wanxian, and Yichang, respectively, and thirteen and sixteen tests completed at Shashi and Jianli, respectively. Observations included water level, velocity, sediment concentration, bed material, suspended sediment particle, and water temperature data. A summary of the experiments is shown in Table 1.

\section{Near-bed suspended sediment experiment}

In the experiments, the multithread/point method was adopted when testing on the discharge and velocity. The specific number of threads and points would change case by case. According to the section width, the 21, 26, 13, 22, and 28 threads were used respectively on the Qingxichang,
Wanxian, Yichang, Shashi, and Jianli cross-sections. There were seven points on each thread. If the relative positions of the riverbed and water surface were 0 and 1 , then the relative positions of the measurement points were 1.0, 0.8, 0.4, 0.2, $0.1,0.5 \mathrm{~m}$, and $0.1 \mathrm{~m}$. The relative positions of the measurement points are shown in Fig. 2. However, when the relative water depth of 0.1 was $0.5 \mathrm{~m}$ from the riverbed, six points were used. Moreover, the test was able to choose a vertical line near the river bank according to the water level and river width.

The locations of the vertical lines for the suspended sediment measurements were the same as those for the discharge and velocity tests. A horizontal sampler was used at four test points close to the water surface, and the relative position of the vertical line for the near-bed suspended sediment sampler was 0.1 times the water depth and $0.5 \mathrm{~m}$ and $0.1 \mathrm{~m}$ away from the riverbed (Fig. 3).

\section{Analysis of test results}

In this study, the common method used multithread/point method data but only selected conventional observation points

Table 1 Summary of experiments

\begin{tabular}{lllllll}
\hline Sections & Runs & $\begin{array}{l}\text { Range of } \\
\text { depth }(\mathrm{m})\end{array}$ & $\begin{array}{l}\text { Range of } \\
\text { velocity }(\mathrm{m} / \mathrm{s})\end{array}$ & $\begin{array}{l}\text { Range of } \\
\text { discharge }\left(\mathrm{m}^{3} / \mathrm{s}\right)\end{array}$ & $\begin{array}{l}\text { Range of sediment } \\
\text { concentrations }\left(\mathrm{kg} / \mathrm{m}^{3}\right)\end{array}$ & $\begin{array}{l}\text { Range of sediment transport } \\
\text { rate }\left(10^{3} \mathrm{~kg} / \mathrm{s}\right)\end{array}$ \\
\hline Qingxichang & 13 & $23.7-31.2$ & $0.25-1.39$ & $3940-16600$ & $0.004-0.723$ & $0.016-12.0$ \\
Wanxian & 14 & $35.8-49.9$ & $0.12-1.01$ & $4180-25400$ & $0.004-1.470$ & $0.017-37.30$ \\
Yichang & 8 & $12.3-19.9$ & $0.93-2.34$ & $8550-35600$ & $0.012-0.20$ & $0.10-6.37$ \\
Shashi & 13 & $5.3-12.3$ & $0.77-1.79$ & $4520-24800$ & $0.029-0.348$ & $0.161-8.643$ \\
Jianli & 16 & $5.3-11.9$ & $0.68-1.58$ & $4590-21900$ & $0.050-0.414$ & $0.249-9.06$ \\
\hline
\end{tabular}


Fig. 2 Schematic diagram of threads and points (Yichang, 13 Dec. 2006)

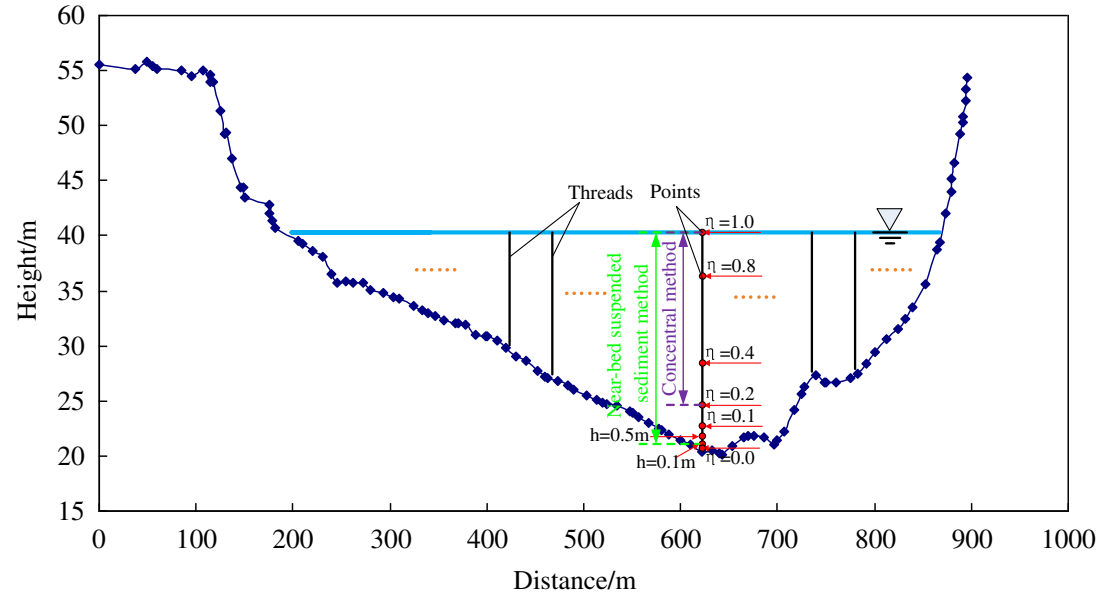

for calculations. The improved method used all of the multithread/point method data for calculations. Errors of the common method and the improved method may be caused by measurement errors from area, discharge, velocity, suspended sediment concentration, and other data. For example, a comprehensive error of sediment transport rate includes the discharge and suspended sediment concentration errors, while the discharge error is a combination of the velocity and area errors. The areas used for the two methods were almost the same. The differences in flow, velocity, suspended sediment concentration, and sediment transport rate results of the two methods at the five sections are discussed below.

\section{Discharge results}

According to the test results, for only one run, the maximum error was $3.58 \%$, while for multiple runs, the relative errors

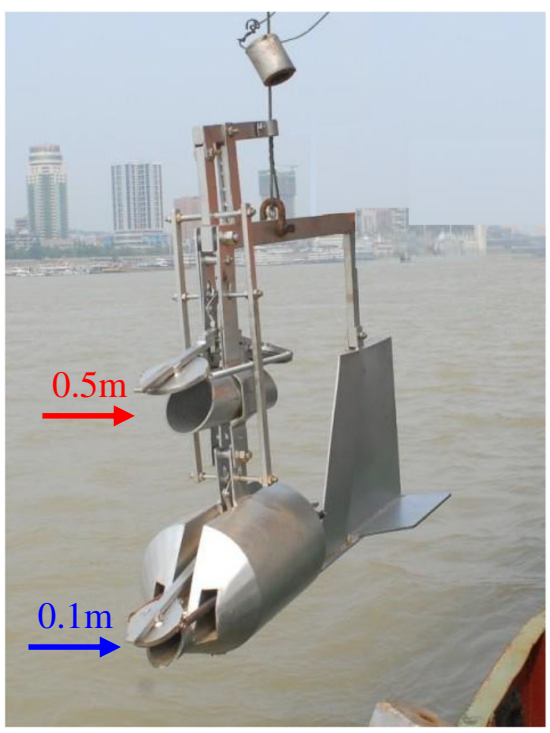

Fig. 3 Sampler of near-bed suspended sediment were less than $2 \%$. All test runs showed that the discharges at each section determined by the common method were larger than those determined by the improved method. This result can also be seen in Fig. 4.

Figure 4 elaborates the comparison of discharges determined by the common method and the improved method. The discharges of the common method ranged between 99.67 and $103.58 \%$ of the discharges of the improved method. Then, regression and correlation analyses were performed on all measured points. The relationship between the methods can be shown as follows:

$Q_{b}=Q_{c} / 101.4 \%$

where $Q_{b}$ is the discharge of the improved method and $Q_{c}$ is the discharge of the common method. Only a $1.4 \%$ difference was observed between the two methods. Therefore, the common method met the accuracy requirement of discharge measurements.

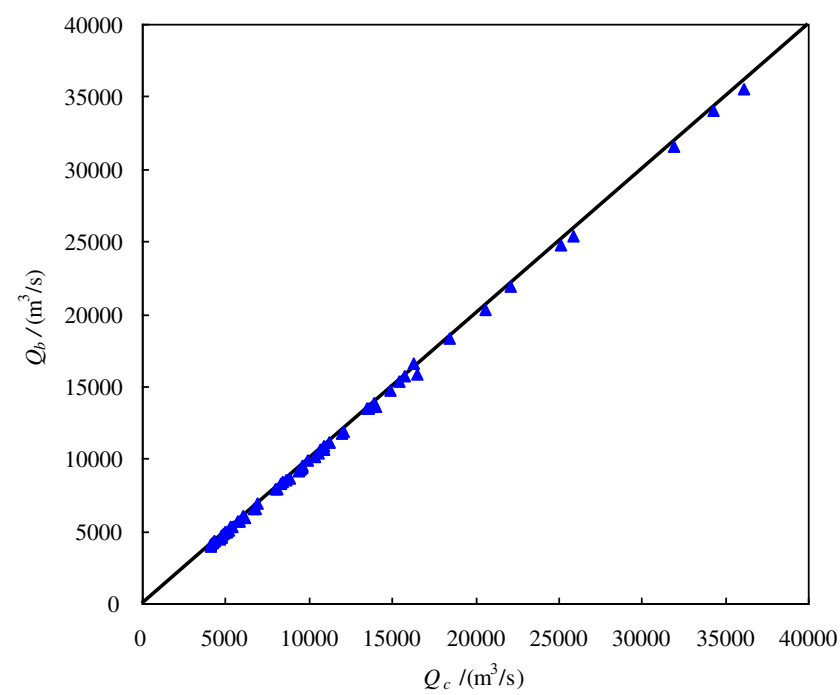

Fig. 4 Discharge comparisons between the common method and improved method 


\section{Velocity results}

For the velocity results with one run in each of the five hydrologic sections, the maximum velocity error was $3.70 \%$. In contrast, the relative error of the multirun velocity results was no more than $2 \%$. Moreover, the velocity of the common method was larger than that of the improved method.

Figure 5 compares the velocities of the two methods. The velocity of the common method ranged between 100 and $104 \%$ of the velocity of the improved method. When $V \leq$ $0.50 \mathrm{~m} / \mathrm{s}$, the results of the two methods had little variability, with percent similarities close to $100 \%$, while when $V>0.50$ $\mathrm{m} / \mathrm{s}$, these percentages slightly increased. Regression analysis was also performed at all the measurement points. The relationship was given by

$V_{b}=\left\{\begin{array}{cc}V_{\mathrm{c}} / 100.4 \% & (V \leq 0.50 \mathrm{~m} / \mathrm{s}) \\ V_{\mathrm{c}} / 101.5 \% & (V>0.50 \mathrm{~m} / \mathrm{s})\end{array}\right.$

where $V_{b}$ is the velocity from the improved method and $V_{c}$ is the velocity from the common method. Equation (2) shows that the common method met the velocity accuracy requirements, and when the velocity was less than $0.5 \mathrm{~m} / \mathrm{s}$, both of the methods yielded the same results.

\section{Results of suspended sediment concentration}

Regarding the suspended sediment concentration, there were seven test runs with relative errors greater than $5 \%$, four test runs with relative errors greater than $10 \%$, and three test runs with relative errors greater than $20 \%$ at the Shashi section. At the Jianli Section, there were five test runs with relative errors greater than $5 \%$, four test runs with relative errors greater than $10 \%$, and two test runs with relative errors greater than $20 \%$.

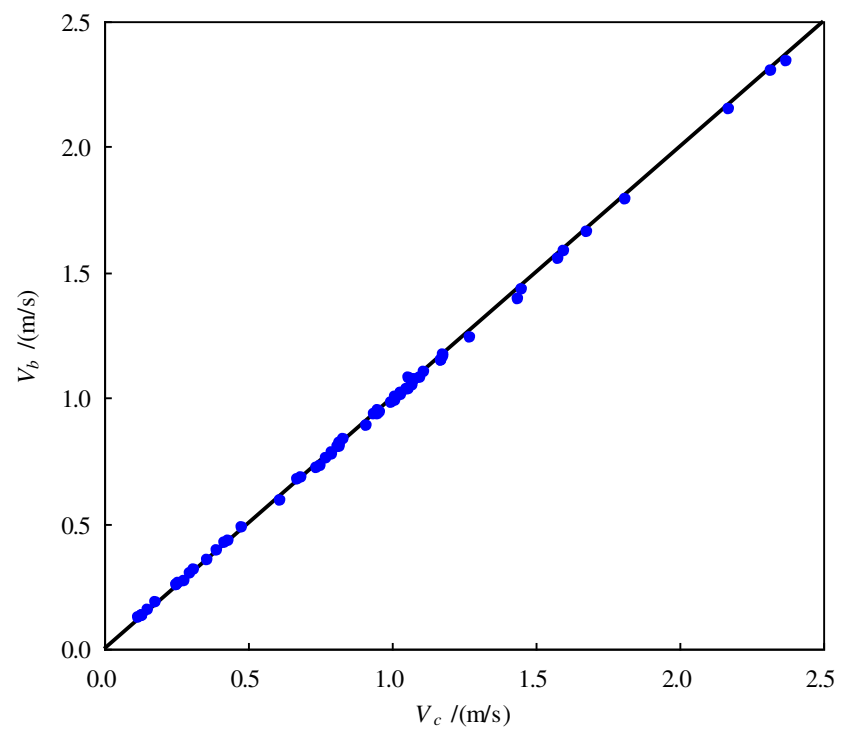

Fig. 5 Velocity comparisons between the common method and improved method
The maximum relative error of the three other sections was less than 5\%. The relative errors at Shashi and Jianli were much larger than those at the other three sections.

For the test results from the Qingxichang, Wanxian, and Yichang sections, when $Q \leq 9000 \mathrm{~m}^{3} / \mathrm{s}$, only one run among 15 runs appeared a measurement error. That meant the results from the common method were significantly consistent with the results from the improved method if accidental errors were considered. During the flood season (from May to Oct.), the suspended sediment concentration errors ranged between -4.55 and $4.07 \%$. The mean value was $0.99 \%$. Therefore, errors existed.

However, for the test results at Shashi and Jianli, there were large variations in the suspended sediment concentrations, with values ranging from -20 to $30.95 \%$ and -20.74 to $25.26 \%$, respectively, and there was no relationship between the suspended sediment concentration and discharge and velocity. Figure 6 shows the relationship between these two methods, with a slope greater than 1.0. This means that when using the common method, missing calculations or missing tests for the suspended sediment concentration results emerged.

\section{Results of sediment transport rate}

During this experimental period, there were thirteen runs at the Qingxichang section, and for two of these runs, the errors exceeded 5\%. Fourteen runs were conducted at Wanxian, two of which had errors more than 5\%. Thirteen runs were conducted at Shashi, eight of which had errors greater than 5\%, four of which had errors greater than $15 \%$, and two of which had relative errors greater than $30 \%$. At the same time, among the sixteen runs at Jianli, five runs had errors larger than 5\%, and four runs had errors greater than $10 \%$, but only one run had a relative error exceeding $25 \%$. Last, the maximum relative error at Yichang was 2.69\%.

Moreover, the sediment transport rate error at each section was larger in the flood season than that in the non-flood season. The sediment discharge in the flood season was more than $80 \%$ of the annual sediment discharge in the Yangtze River; therefore, the sediment transport rate error during the flood season had a large sediment discharge component.

\section{Sediment discharge correction}

\section{The vertical distribution of generalized velocity}

Halper and McGrail (1988) showed that the current direction is closely related to changes in the suspended sediment concentration. According to the measured data, the relative velocity along the water depth from the improved method basically had an exponential 

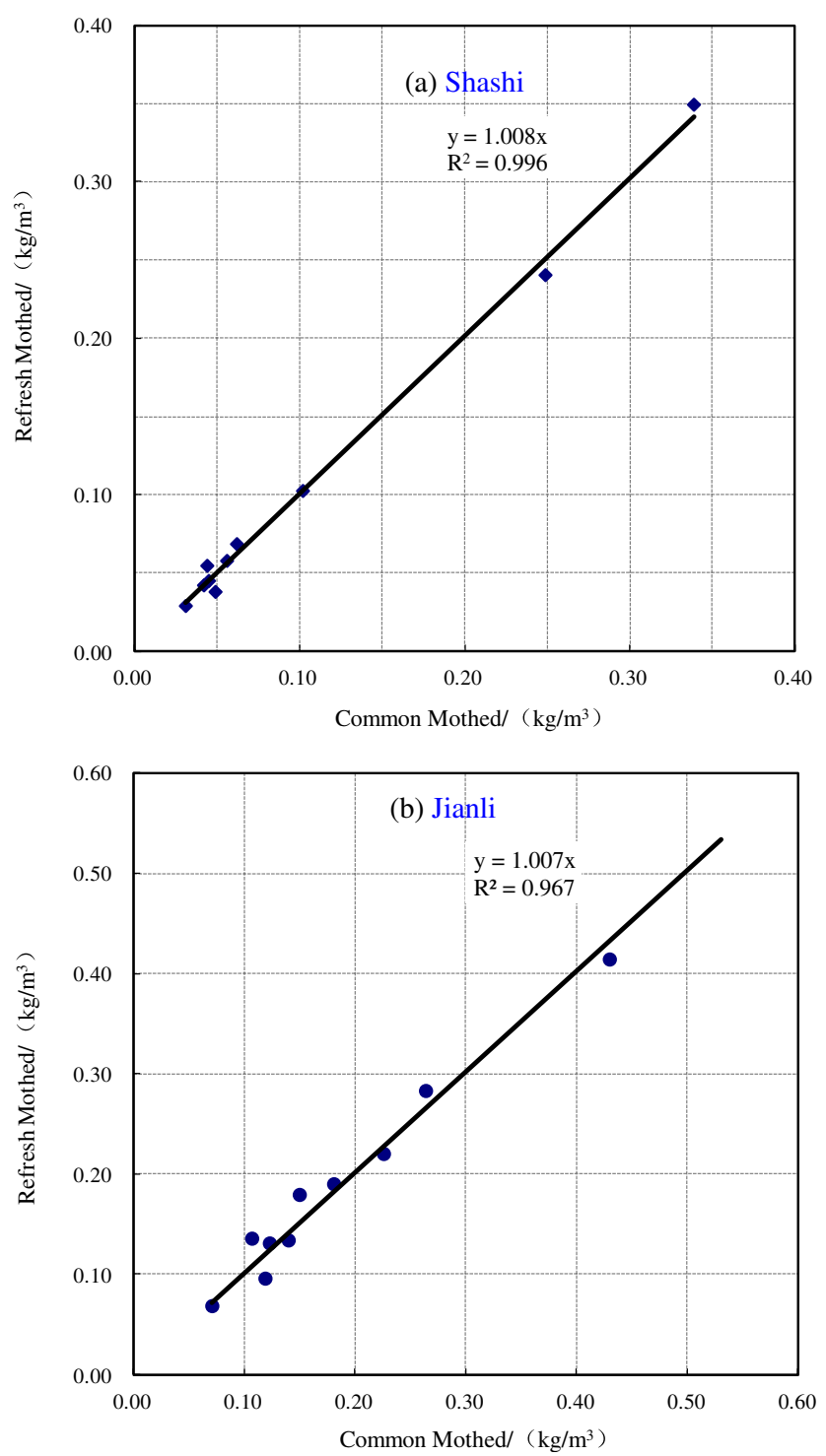

Fig. 6 Average sediment concentration comparisons

distribution. Therefore, using exponential fitting, Eq. (3) presents the synthetically generalized curvilinear relationship, which can be written as

$\frac{V_{\eta}}{\bar{V}}=\left(1+\frac{1}{m}\right) \eta^{\frac{1}{m}}$

where $V_{\eta} / \bar{V}$ is the relative velocity, $\eta$ is the relative depth, and $m$ is the variable parameter.

The above synthetically generalized curvilinear equation of the improved method comes from the actual measurements at each section. On that basis, the multirun synthetically generalized curvilinear equation was fitted according to improved method results when $\eta \geq 0.2$ for the common method to calculate the following sediment discharge correction. Table 2 lists the $m$ values used by the two methods in each section.
The vertical distribution of the generalized suspended sediment concentration

The relative suspended sediment concentration along the water depth from the improved method can be expressed by (O’Brien 1933; Rouse 1938; Wu 2007)

$C_{s \eta}=r\left(\frac{1}{\eta}-1\right)^{z}$

where $C_{S \eta}$ is the sediment concentration with a relative depth of $\eta$, ris a coefficient, and $z$ is the suspension or Rouse number. Physically, $z$ represents the effect of gravity against turbulent diffusion. When $z$ is larger, the effect of gravity is stronger, and the distribution of the sediment concentration along the vertical direction is less uniform. When $z$ is smaller, the effect of turbulent diffusion is stronger, and the distribution of the sediment concentration is more uniform. Wu (2007) reported that when the Rouse number is larger than approximately 5.0, the relative concentration of suspended sediment is quite small, and when the Rouse number is less than approximately 0.06 , the suspended sediment concentration is almost uniformly distributed along the depth.

From Eq. (4), the relative suspended sediment concentration, $C_{s \eta} / C_{s 0.2}$, can be written as

$\frac{C_{s \eta}}{C_{s 0.2}}=\left(\frac{1}{0.2}-1\right)^{-z}\left(\frac{1}{\eta}-1\right)^{z}=k\left(\frac{1}{\eta}-1\right)^{z}$

where $C_{s 0.2}$ is the suspended sediment concentration where $\eta=0.2$, and $k$ and $z$ are variable parameters.

The above synthetically generalized curvilinear equation comes from actual measurements at each section. On that basis, the curvilinear equation with $\eta \geq 0.2$ was used by the common method to calculate the following sediment discharge correction coefficients. Table 3 lists the values of $k, z$ used by the improved method and the common method at each section.

\section{Correction coefficients of sediment discharge}

The correction coefficient of sediment discharge was the ratio of the sediment discharge from the synthetically generalized curvilinear equation to that from norm stipulating.

The correction coefficient at each section can be calculated by

$\theta_{\mathrm{d}_{\mathrm{i}}}=\int_{A}^{1} \eta^{\frac{1}{m}}\left(\frac{1}{\eta}-1\right)^{z} d \eta / \sum_{\eta} K_{\eta}^{\prime} \eta^{\frac{1}{m}}\left(\frac{1}{\eta}-1\right)^{z}$

where $\theta_{\mathrm{d}_{\mathrm{i}}}$ is the correction coefficient of the $d_{i}$ group of bed-material load discharge and $K_{\eta}^{\prime}$ is the depth weight. 
Table 2 Parameters that synthetically generalized the relative velocity curve used by each section

\begin{tabular}{lll}
\hline Formula & $\frac{V_{\eta}}{\bar{V}}=\left(1+\frac{1}{m}\right) \eta^{\frac{1}{m}}$ & \\
\cline { 2 - 3 } Method & $\begin{array}{l}\text { Multipoint } \\
\text { method }\end{array}$ & $\begin{array}{l}\text { Conventional } \\
\text { method }\end{array}$ \\
\hline Parameter & $1 / m$ & $1 / m^{\prime}$ \\
Qingxichang & 0.089 & 0.091 \\
Wanxian & 0.156 & 0.144 \\
Yichang & 0.143 & 0.144 \\
Shashi & 0.163 & 0.160 \\
Jianli & 0.185 & 0.179 \\
\hline
\end{tabular}

For the Yangtze River, $A=0$ (Han 2008). In this study, the suspended sediment was group $d_{i}$; thus, the correction coefficient of sediment discharge, $\theta_{\mathrm{d}}$, was written as

$$
\begin{aligned}
\theta_{\mathrm{d}} & =\int_{0}^{1} \eta^{\frac{1}{m}}\left(\frac{1}{\eta}-1\right)^{z} d \eta / \sum_{\eta} K_{\eta}^{\prime} \eta^{\frac{1}{m}}\left(\frac{1}{\eta}-1\right)^{z} \\
& =\left(\frac{1}{M}-\frac{z}{M+1}-\frac{z(z-1)}{2(M+2)}-\frac{z(z-1)(z-2)}{6(M+3)}\right) / \sum_{\eta} K_{\eta}^{\prime} \eta^{\frac{1}{m}}\left(\frac{1}{\eta}-1\right)^{z}
\end{aligned}
$$

where $M=1 / m-z+1$. The correction coefficients obtained by Eq. (7) are listed in Table 4.

\section{Calculation of sediment discharge}

The total discharge of sediment $\left(W_{s}\right)$ after correction is

$W_{s}=\theta_{\mathrm{d}} \cdot W_{s}^{\prime}$

where $W_{s}^{\prime}$ is the sediment discharge without correction.

$K_{t}$ is the ratio between the correction amount and the sediment discharge without correction.

$K_{t}=\left(W_{s}-W_{s}^{\prime}\right) / W_{s}^{\prime} \cdot 100 \%$

Using Eqs. (8) and (9), during Jul. 2006 to May 2007, the sediment discharge correction results at each section were
Table 4 Correction coefficient of each section for the sediment discharge

\begin{tabular}{ll}
\hline Section & $\theta_{\mathrm{d}}$ \\
\hline Qingxichang & 1.0081 \\
Wanxian & 1.0085 \\
Yichang & 1.0049 \\
Shashi & 1.3217 \\
Jianli & 1.3697 \\
\hline
\end{tabular}

determined and are shown in Table 5. (i) Qingxichang, Wanxian, and Yichang had almost no corrections, while Shashi and Jianli had a greater correction, which was basically consistent with the missed measurements at each section described in "Results of suspended sediment concentration." (ii) When calculating the sediment discharges at Shashi and Jianli, the influence of near-bed suspended sediment must be considered. The sections of Qingxichang and Wanxian were located in the reservoir, with velocities smaller than those of Shashi and Jianli, and Yichang had reached a balance between scour and deposition; therefore, the errorsat Qingxichang, Wanxian, and Yichang were small. At Shashi and Jianli, the sediment discharge errors were larger than $30 \%$. This is because the riverbed scouring at these two sections was stronger than that at the other sections, which caused the total near-bed sediment discharge to be large.

The sediment concentration errors were small at both the reservoir sections and dynamic equilibrium sections, while the greater error was observed in the intensively scoured riverbed. There was no significant relationship among the sediment concentration, flow and velocity, and the phenomenon of missed measurements also occurred.

\section{Validation of the test results}

Qingxichang and Wanxian which were in the TGR required almost no corrections; therefore, the validation of the test results only considered the downstream region of the Three Gorges Dam.
Table 3 Parameters that synthetically generalized the sediment concentration curve used by each section

\begin{tabular}{lllll}
\hline Formula & $\frac{\mathrm{C}_{s \eta}}{C_{s 0.2}}=k\left(\frac{1}{\eta}-1\right)^{z}$ & & \\
\cline { 2 - 5 } Method & Multipoint method & \multicolumn{2}{l}{ Conventional method } \\
\hline Parameter & $k$ & $z$ & $k^{\prime}$ & $z^{\prime}$ \\
Qingxichang & 0.994 & 0.009 & 1.005 & 0.011 \\
Wanxian & 1.018 & 0.024 & 1.005 & 0.018 \\
Yichang & 1.011 & 0.009 & 0.993 & 0.004 \\
Shashi & 1.091 & 0.227 & 0.922 & 0.150 \\
Jianli & 1.046 & 0.268 & 0.933 & 0.224 \\
\hline
\end{tabular}


Table 5 Comparison between the bathymetric comparison and sediment loading measurements

\begin{tabular}{|c|c|c|c|c|c|c|c|c|c|}
\hline \multirow[t]{3}{*}{ Reaches } & \multicolumn{2}{|c|}{ Bathymetric comparison } & \multicolumn{7}{|c|}{ Sediment loading measurements } \\
\hline & \multirow[t]{2}{*}{$10^{4} \mathrm{~m}^{3}$} & \multirow[t]{2}{*}{$10^{4} \mathrm{t}$} & \multirow{2}{*}{$\begin{array}{l}\text { Upstream } \\
\text { hydrological } \\
\text { station }\left(10^{4} \mathrm{t}\right)\end{array}$} & \multirow{2}{*}{$\begin{array}{l}\text { Downstream } \\
\text { hydrological } \\
\text { station }\left(10^{4} \mathrm{t}\right)\end{array}$} & \multirow[t]{2}{*}{ Tributary $\left(10^{4} \mathrm{t}\right)$} & \multicolumn{2}{|l|}{ Not corrected } & \multicolumn{2}{|l|}{ Corrected } \\
\hline & & & & & & $\begin{array}{l}\text { Sediment } \\
\text { discharge }\left(10^{4} t\right)\end{array}$ & Error & $\begin{array}{l}\text { Sediment discharge } \\
\left(10^{4} t\right)\end{array}$ & Error \\
\hline Yichang Shashi & -5871 & -7926 & 5231 & 7556 & 851 & -3176 & 59.93 & -5581 & 29.58 \\
\hline Yichang Jianli & -8297 & -11201 & 5231 & 9174 & 1330 & -5273 & 52.92 & -8639 & 22.87 \\
\hline Shashi Jianli & -2426 & -3275 & 7556 & 9174 & 479 & -2097 & 35.97 & -3058 & 6.63 \\
\hline
\end{tabular}

According to the results, three reaches were chosen: Yichang-Shashi, Yichang-Jianli, and Shashi-Jianli. The calculated period was from October 2006 to October 2007. It was assumed that the sediment discharge calculated by the bathymetric comparison was correct. The results are shown in Table 5. When the sediment discharge was corrected by the test results, the error was greatly reduced by approximately $30 \%$. However, this did not mean that there was no error, as the calculation results of bathymetric comparisons and sediment loading measurements are affected by many factors, such as the dry bulk density, sand mining, and bank erosion.

\section{Conclusions}

Near-bed suspended sediment experiment data at the sections of Qingxichang, Wanxian, Yichang, Shashi, and Jianli at the early operation stage of the TGR were chosen to separately analyze differences between the common method and the improved method for measuring discharge, velocity, suspended sediment concentration, and sediment discharge rate. Several conclusions can be drawn from this study. (i) The discharges and velocities at each section determined by the common method were slightly larger than those determined by the improved method; therefore, the common method meets the measurement requirements. (ii) The sediment concentration error at the reservoir section and the section in equilirium were small, while the more the river bed was scoured, the larger the error in the sediment concentration occurred. And there were no relationships between discharges and velocities. Missed measurements also occurred. However, the error of the sediment discharge was affected by that of the suspended sediment concentration. The error was large at sections undergoing strong scour during flood seasons. (iii) The sediment discharge correction coefficients at each section showed that the sediment discharge should be corrected if the total near-bed sediment discharge is large. Then, the test results were applied to calculate the sediment discharge of three rivers, and the results indicated that the correction reduced the gap between bathymetric comparisons and sediment load measurements.
However, it should be noted that the total sediment concentration from the presented data was small during the test period, which limited the representativeness of the test (The Ministry of Water Resources of the People's Republic China 2008). In the future study, data from normal, wet, and sediment-laden years could also be considered to improve the improved method.

Acknowledgments We appreciate the Changjiang Water Resources Commission (CWRC) for providing the data used in this study.

Funding This work was supported by the National Key Research and Development Program of China (2016YFC0402303).

Open Access This article is licensed under a Creative Commons Attribution 4.0 International License, which permits use, sharing, adaptation, distribution and reproduction in any medium or format, as long as you give appropriate credit to the original author(s) and the source, provide a link to the Creative Commons licence, and indicate if changes were made. The images or other third party material in this article are included in the article's Creative Commons licence, unless indicated otherwise in a credit line to the material. If material is not included in the article's Creative Commons licence and your intended use is not permitted by statutory regulation or exceeds the permitted use, you will need to obtain permission directly from the copyright holder. To view a copy of this licence, visit http://creativecommons.org/licenses/by/4.0/.

\section{References}

Abelson A, Miloh T, Loya Y (1993) Flow patterns induced by substrata and body morphologies of benthic organisms, and their roles in determining availability of food particles. Limnol Oceanogr 38(6): $1116-1124$

Betteridge KFE, Thorne PD, Bell PS (2002) Assessment of acoustic coherent Doppler and cross-correla-tion techniques for measuring near-bed velocity and suspended sediment profiles in the marine environment.J. J Atmos Ocean Technol 19(3):367-380

Betteridge KFE, Williams JJ, Thorne PD, Bell PS (2003) Acoustic instrumentation for measuring near-bed sediment processes and hydrodynamics. J Exp Mar Biol Ecol 285-286:105-118

Betteridge KFE, Thorne PD, Cooke RD (2008) Calibrating multifrequency acoustic backscatter systems for studying near-bed suspended sediment transport processes. Cont Shelf Res 28:227235 
Cacchione DA, Thorne PD, Agrawal Y, Nidzieko NJ (2008) Timeaveraged near-bed suspended sediment concentrations under waves and currents: comparison of measured and model estimates. Cont Shelf Res 28:470-484

Cao Z (1999) Equilibrium near-bed concentration of suspended sediment. J Hydraul Eng ASCE 115(12):1270-1278

Celik I, Rodi W (1988) Modeling suspended sediment transport in nonequilibrium situations. J Hydraul Eng ASCE 114:1157-1191

Christopher EV, Daniel MH (2002) The accumulation and decay of nearbed suspended sand concentration due to waves and wave groups. Cont Shelf Res 22:1987-2000

CWRC (Changjiang Water Resources Commission) (2017) Analysis of channel degradation in the reach downstream of the Three Gorges Dam. Scientific Report of CWRC, Wuhan (In Chinese)

Drake DE (1989) Estimates of the suspended sediment reference concentration $\left(\mathrm{C}_{\mathrm{a}}\right)$ and resuspension coefficient $\left(\tau_{0}\right)$ from near-bottom observations on the California shelf. Cont Shelf Res 9(1):51-64

Einstein HA (1950) The bed-load function for sediment transportation in open channel flows. Technical Bulletin No.1206, U.S. Department of Agriculture, Soil Conservation Service, Washington D.C., USA

Friedrichs M, Leipe T, Peine F, Graf G (2009) Impact of macrozoobenthic structures on near-bed sediment fluxes. J Mar Syst 75:336-347

Garcia M, Parker G (1991) Entrainment of bed sediment into suspended. J Hydraul Eng ASCE 117(4):414-1433

Halper FB, McGrail DW (1988) Long-term measurements of nearbottom currents and suspended sediment concentration on the outer Texas-Louisiana continental shelf. Cont Shelf Res 8(1):23-36

Han QW (2008) Error analysis of coarse suspended load measuring. J China Hydrol 28(1):1-7 (in Chinese)

Hossain S, Eyreb B (2002) Suspended sediment exchange through the subtropical Richmond River estuary, Australia: a balance approach. Estuar Coast Shelf Sci 55:579-586

Jiang WS, Wang HJ (2005) Distribution of suspended matter and its relationship with bed sediment particle size in Laizhou bay. Oceanol Limnol Sin 36:97-103

Liu H, He Q, Wang ZB, Weltje GJ, Zhang J (2010) Dynamics and spatial variability of near-bottom sediment exchange in the Yangtze Estuary, China. Estuar Coast Shelf Sci 86:322-330

Liu G, Wu J, Wang Y (2014) Near-bed sediment transport in a heavily modified coastal plain estuary.International Journal of Sediment Research. Vol. 29:232-245

O'Brien MP (1933) Review of the theory of turbulent flow and its relationship to sediment transportation. Trans Am Geophys Union 14: 487-491

Palanques J, Puig P, Guillén J, Jiménez J, Gracia V, Sánchez-Arcilla A, Madsen O (2002) Near-bottom suspended sediment fluxes on the microtidal low-energy Ebro continental shelf (NW Mediterranean). Cont Shelf Res 22:285-303

Pang W, Dai Z, Ge Z, Li S, Mei X, Gu J, Hu H (2019) Near-bed crossshore suspended sediment transport over a meso-macro tidal beach under varied wave conditions. Estuar Coast Shelf Sci 217:69-80

Puig AP, Palanques JG (2001) Near-bottom suspended matter concentration on the Continental Shelf during storms estimates based on in situ observations of light transmission and a particle size dependent transmissometer calibration. Mar Geol 178:81-93

Ren J, Packman AI (2007) Changes in fine sediment size distributions due to interactions with streambed sediments. Sediment Geol 202: 529-537

Roser C, Lakhanpal G, Stewardson MJ (2018) The relative contribution of near-bed vs. intragravel horizontal transport to fine sediment accumulation processes in river gravel beds. Geomorphology 303: 299-308

Rouse H (1938) Experiments on the mechanics of sediment suspension. In: Proceedings of the fifth international congress for applied mechanics. J. Wiley, New York, pp 550-554

Sarma KVN, Lakshminarayana P, Rao NSL (1983) Velocity distribution in smooth rectangular open channels. J Hydraul Eng 109(2):270 289

Schettini CAF (2002) Near bed sediment transport in the itajaí-açu river estuary, southern brazil. Proc Mar Sci 5:499-512

Smith JD, McLean SR (1977) Spatially averaged flow over a wavy surface. J Geophys Res 82(12):1735-1746

Sottolichio A, Hurther D, Gratiot N, Bretel P (2011) Acoustic turbulence measurements of near-bed suspended sediment dynamics in highly turbid waters of a macrotidal estuary.Continental ShelfResearch. Vol. 31:S36-S49

The ministry of water resources of the People's Republic China (2008) Rivers Sediment Bulletin in China 2007, Beijing: China water conservancy and hydropower press. pp 1-17. (in Chinese)

Van Rijn LC (1984) Sediment transit, part II: suspended load transport. J Hydraul Eng ASCE 110(11):1613-1641

Wang Y, Rhoads BL, Wang D, Wu J, Zhang X (2018) Impacts of large dams on the complexity of suspended sediment dynamics in the Yangtze River. J Hydrol 558:184-195

Wang H, Menglu L, Cece S, Wu W, Xiangbin R, Jiaye Z (2020) Variability in water chemistry of the Three Gorges Reservoir, China. Heliyon 6(4): 03610

$\mathrm{Wu}$ W (2007) Computational river dynamics. Taylor \& Francis, London, p 508

Xiang ZA (1988) The near-bed suspended sediment test and related test equipment. J China Hydrol 6:9-14 (in Chinese)

Yuan J, Li Z, Madsen OS (2017) Bottom-slope-induced net sheet-flow sediment transport rate under sinusoidal oscillatory flows. J Geophys Res Oceans 122(1):236-263 